\title{
Case Study of Assignment Teaching Combined with Psychological Education
}

\author{
Chen $\operatorname{Yan}^{1, \mathrm{a}}$ \\ ${ }^{1}$ Nanjing Xinyuan Primary School, Nanjing, Jiangsu Province, China \\ a1072460117@qq.com
}

\begin{abstract}
Primary school students are under a lot of psychological pressure when writing essays, and they cannot always find inspiration for their work. After the new crown epidemic, pressure from all sides has brought certain tests to children's psychological education. The author takes the eighth unit "My Heart is Beating" as an example to study the method of combining the teaching of exercises with psychological education, using an equal, cooperative and pleasant atmosphere to stimulate students' interest in writing. It can not only improve the level of composition, but also allow students to relieve stress and relieve emotions.
\end{abstract}

Keywords: assignment teaching, psychological education, life experience

\section{习作教学结合心理教育的案例研究}

陈雁 $1, \mathrm{a}$

${ }^{1}$ 南京市金园小学, 南京, 江苏省, 中国

1072460117@qq.com

\section{摘要}

小学生写作文心理压力大, 总是找不到习作的灵感。新冠疫情过后, 来自方方面面的压力, 给儿童心理教育带 来一定的考验。笔者以统编版语文四年级上册第八单元习作 “我的心儿怦怦跳” 为例, 研究习作教学结合心理 教育的方法, 用一种平等、合作、愉快的氛围, 激发学生习作兴趣, 既能提高作文水平, 又能让学生排解压力, 舒缓情绪的策略。

关键词: 习作教学 心理教育 生活体验

\section{1. 案例背景}

当前, 随着社会的发展, 生活节奏加快, 再加上 全球迎来百年不遇的疫情危机, 疫情过后, 来自方方 面面的压力, 给儿童心理教育带来一定的考验。儿童 心理健康对今后的成长有着深远的影响。尤其是习作 教学, 如何克服学生写作文心理压力大, 难以找到习 作的灵感的情况? 如何结合心理教育方法激发学生 习作兴趣, 在教学中既能学到语文知识, 提高作文水 平, 又能让学生排解压力, 舒缓情绪, 产生开心、快 乐的作文体验呢?

语文老师很多都是兼任班主任和心理辅导教师
的, 中小学心理健康教育指出, 培养教育青少年, 不 仅要引导他们树立理想信念, 培养高尚品格, 而且要 培养他们的美好心灵和良好心态, 未成年人心理健康 成为目前关注的重要方面。笔者一直对语文教学中渗 透心理教育非常感兴趣, 多次参加心理健康培训, 面 对当前学生的心理现状, 认真思考满足学生发展需求 的策略。

统编版小学语文四年级上册第八单元习作“我的 心儿怦怦跳”, 对自己经历的生活或学习场景, 提出 了“你有过上面的经历吗”“当时心情是怎样”等问题, 通过呈现“害怕、激动、紧张、”等心理状态的图例, 
要求唤醒学生内心体验, 写清楚内心的感受。确实, 到了小学中高年级, 很多同学都有害怕、紧张、担心 的经历。基于学生学情, 安排了一次此次习作教学的 尝试: 结合心理教育, 进行习作指导[1]。

\section{2. 案例描述和分析}

课堂上, 首先出示绘本《我的尾巴》。书中写了 一个小朋友的紧张、害怕的过程。一天, 主人公发现 背后长出了一条奇怪的尾巴, 他非常担心同学会嘲 笑。于是, 他就千方百计地隐藏自己的尾巴, 想尽一 切办法不让同学和老师看见。通过抓住学生的好奇 心, 一边讲故事, 一边猜测故事的发展。带领学生探 究文中小主人公的“隐藏方法”, 分析主人公的对策。 以下是教学中的师生课堂实录片段。

师: 同学们, 见过生活当中有人长尾巴么? 《我 的尾巴》这本书你们看过吗?

生: 没有。

生: 怎么可能有人长尾巴呢?

生：我想知道故事讲什么?

师: 假如你有一天长出一条长尾巴, 你会怎样? 想不想看一看呢? 看看书中小朋友遇到什么样的事 情?

(激发学生兴趣, 产生急于探究的心理。对故事 的发展, 对人物结局的猜测, 产生强烈的兴趣, 对习 作表达有了期待。)

\section{生：想！}

师: 让我们一起来看一看。当主人公长出尾巴后 心理怎样想? 同学们可以观察图片中人物的表情, 猜 测人物的内心。

生: 害怕。心儿怦怦跳。

生: 紧张。不想让别人知道。

师：那就想什么办法呢?

生：遮挡起来，不让别人发现。

师：他怎么做的？

生：把尾巴塞进裤子，穿爸爸的衣服，

师: 是呀, 出现问题, 紧张得心儿怦怦跳, 怎么 做? 穿爸爸的衣服, 把尾巴藏起来。这是“第一 招”一掩饰。那么, 第二、第三招呢? 一共用了几 招？小组合作填写下列表格。
表 1 心跳指数测量表

\begin{tabular}{|c|c|c|c|}
\hline 序号 & 做法 & 招术 & 心跳指数 \\
\hline $\begin{array}{c}\text { 第一 } \\
\text { 招 }\end{array}$ & $\begin{array}{c}\text { 把尾巴塞进裤子,藏起 } \\
\text { 来 }\end{array}$ & 掩饰 & $\star \star$ \\
\hline $\begin{array}{c}\text { 第二 } \\
\text { 招 }\end{array}$ & $\begin{array}{c}\text { 悄悄躲在幽深的小巷 } \\
\text { 子里 }\end{array}$ & 躲避 & $\star \star \star$ \\
\hline $\begin{array}{c}\text { 第三 } \\
\text { 招 }\end{array}$ & $\begin{array}{c}\text { 在校门口走来走去, 不 } \\
\text { 敢进校门 }\end{array}$ & 徘徊 & $\star \star \star$ \\
\hline $\begin{array}{c}\text { 第四 } \\
\text { 招 }\end{array}$ & $\begin{array}{c}\text { 请求同学敏佳, 为他保 } \\
\text { 守秘密 }\end{array}$ & 请求 & $\star \star$ \\
\hline
\end{tabular}

（和孩子们一起体会故事的跌宕起伏，体会主人 公的心路历程, 分析他的心理变化, 并体验心跳指 数。）

师：同学们，你们生活中有没有紧张、害怕得“心 儿怦怦跳”的时刻？今天我们就可以练习写一写。

师：可以说说你们的故事吗？参照你的心跳指 数, 分享你的故事。

生: 没有好好上课, 学习成绩退步了, 被家长询 问时心怦怦直跳。

生：课堂上发生意外的一件事，墨水把习字册弄 脏了，担心老师批评。

生：妈妈出差不在家，没有认真复习，考试没考 好。

生: 参加大队委竞选前, 紧张得心怦怦跳。

生：第一次当众讲故事。

师: 如果这样写的话, 一句话就写完了, 《我的 尾巴》对你写心理状况有什么启发？

生: 可以按照“掩饰——躲避——徘徊——请求” 这四招来写。

师: 对呀, 可以通过心里的感受变化来写清事情 的经过，这样写作文有什么好处?

生: 这样就会显得曲折生动, 引起读者的共鸣。

\section{3. 案例反思}

\section{1. 选择合适的习作教学内容, 开展儿童心理 教育。}

\subsection{1, 紧张、害怕是学生常见的情绪体验。}

《中小学心理健康教育》指出: “青少年常见的 情绪问题包括焦虑、抑郁、害怕、愤怒、自卑......” 这些负面情绪积压时间长了, 就成为心中的烦恼。据 研究，小学生有焦虑心态和负面情绪的学生比例很 高, 以下就是对四年级 32 名学生的问卷调查: 
表 2 问卷调查表

\begin{tabular}{|c|c|c|c|}
\hline 序号 & 问题 & $\begin{array}{c}\text { 肯定回答人 } \\
\text { 数 }\end{array}$ & 比例 \\
\hline 1 & $\begin{array}{c}\text { 你经常感到紧张 } \\
\text { 吗? }\end{array}$ & 5 & $15.6 \%$ \\
\hline 2 & $\begin{array}{c}\text { 你经常感到孤独 } \\
\text { 吗? }\end{array}$ & 6 & $18.75 \%$ \\
\hline 3 & $\begin{array}{c}\text { 你是否经常觉得老 } \\
\text { 师不喜欢你? }\end{array}$ & 3 & $9.4 \%$ \\
\hline 5 & $\begin{array}{c}\text { 你有没有对学习丧 } \\
\text { 失信心的时候? }\end{array}$ & 5 & $15.6 \%$ \\
\hline
\end{tabular}

通过调查，比例最高的是“害怕写作文”，可见对 于作文还是有一定的焦虑心理的。比例最低的是“是 否经常觉得老师不喜欢你”这个选项, 说明小孩子绝 大多数喜欢老师, 喜欢校园环境的。但他们的烦恼还 是或多或少体现在日常生活当中，虽然说“少年不识 愁滋味”, 但加强心理健康教育, 已成为教育人的共 识。语文教学要将育人这一核心教育理念渗透到教学 的各个环节, 习作教学中优化心理结构, 促进学生心 理健康发展[2]。

\subsection{2, 合适的心理教育故事可以辅助习作教学。}

害怕得出现“心儿怦怦跳”的事情在四年级学生 身上也不少, 但贸然提出让学生讲, 很可能学生不大 敢说出来, 用一个怎样的点来切入呢? 结合最近四年 级学生喜欢看绘本的特点, 想到绘本阅读《我的尾巴》 一书, 故事主人公为了隐藏自己的尾巴, 经过了“掩 饰、躲避、徘徊、请求”的心路历程, 故事一波三折, 引人入胜, 而这四个心理层次变化正是每个人紧张、 害怕经历的过程。这样的习作仿写结构内容新颖独 特, 使学生对此故事产生了兴趣。渐渐地, 大家敢讲 敢说了。

本次习作过后, 孩子们对绘本阅读产生了浓厚的 兴趣, 班级图书馆中多了很多绘本, 像《大脚个跳芭 蕾舞》《世界上最好的爸爸》 《风到哪里去了》 《爷 爷一定有办法》等, 孩子们对这些“图画书”兴趣浓厚, 笔者也对绘本重新审视和思考, 虽然有的小时候就读 过这种“图画书”, 但现在有了更深的体会, 班里掀起 读绘本的热潮, 这让人始料未及, 也令人感到欣慰, 让孩子爱上阅读, 这不就是我们语文教育的初衷吗?

\section{2. 联系生活实际, 有助于学生产生表达的欲 望。}

\subsection{1, 语文课堂学习场景, 贴近生活。}

陶行知先生的“生活即教育”理论也就是倡导写 作要紧密联系生活。[3]教师在课堂上和大家一起确定
了写作内容的结构, 请大家想一想有没有类似的课堂 经历呢? 在讨论中, 案例中的张同学就讲述了自己写 字课上“心儿怦怦跳”的经历, 老师觉得这个内容很贴 近孩子们的生活，建议他内心发出的独白可以运用 《我的尾巴》中小主人公的四招“隐藏大法”来写。

\subsection{2, 其他活动课场景, 似曾相识。}

学生结合课堂体验, 也有过类似这种心情的时 候, 例如在体育课上做操做得不好被同学嘲笑, 容易 产生紧张、自卑心理, 这个是很多人遇到过的, 内心 活动从 “不好意思” 到 “害怕做” , 再到 “紧张得动 作变形” , 最后 “请求同学别告诉老师”, 具有生动 细淢的心理过程, 通过同桌合作讨论, 学会观察, 学 会思考, 可以帮助学生抓住人物动作、人物内心。音 乐课上, 老师让大家练习小乐器, 学不会的场景再次 重现: 敲鼓节拍不对, 舞蹈动作滑稽可笑, 从 “害怕 得心怦怦跳” 到 “老师千万不要喊我”，再到 “放弃 尝试”, 最后 “躲在同学后面滥笔充数”。这些心理 过程很常见, 学生有话写, 就能写的波澜起伏。

\section{3. 与绘本故事共情, 有助于学生舒缓紧张害 怕的心理。}

\subsection{1, 生活中的体验, 让学生共情。}

美国著名心理学家罗杰斯认为, 设身处地的体会 学生内心的感受, 就是共情, 也叫同感。[4] 习字册 没写好的紧张、成绩不理想害怕被批评……这些都是 常见的生活和学习经历, 如果有细淢的心理体验, 又 有一波三折的故事描写, 文章更加精彩生动。

指导后的学生习作, 收上来批改, 关于写 “紧张、 害怕得心儿怦怦跳”一类的作文中, 很多反应学校生 活中常见的小故事, 例如: 考试成绩有退步, 害怕家 长批评把试卷藏起来, 当家长问的时候 “心儿怦怦 跳” ; 作业没完成, 当老师检查时紧张害怕得 “心儿 怦怦跳”; 参加大队委竞选演讲, 紧张、担心……看 了孩子们的成长故事, 及时通过作文了解他们的心 理, 逐一进行开导。作业没完成的同学, 了解情况, 提出解决问题的方法, 考试退步的同学和她分析原 因, 多多鼓励……告诉孩子们, 把心里话说出来并写 出来, “心儿怦怦跳”后就会慢慢平静下来。

哲学家培根的名言： “如果把快乐告诉朋友, 你 将得到两倍快乐, 如果你把忧愁向朋友倾吐, 你将被 分掉一半的忧愁。” 鼓励孩子们积极动手练笔, 写出 心中的体验。这也是心理教育中的疏导策略。一次作 文, 结合一次心理教育, 收到了意想不到的效果。教 书, 更是育人。

\section{3. 2 , 绘本故事的结局反转, 让学生共情。}

本案例中, 《我的尾巴》故事最后主人公发现每 个人都有 “尾巴”，原来 “尾巴” 就是我们心中的紧 
张和恐惧。只要勇敢说出来, 紧张的心情就会平复, “尾巴” 自然而然就消失了。学生有了表达的欲望, 习作时的体验和感受就更深刻了。

\section{4. 加强沟通和交流, 有助于学生灵动的表 达。}

每个孩子有不同的特点，写作水平也参差不齐， 如何深入地了解他们内心的想法, 根据每个人的特 点, 写出更加灵动有个性的语句呢? 交流和沟通, 就 成了关键，同时也进行心理疏导。

\subsection{1, 与学生的交流。}

前面提到的张同学是一名优秀学生, 他举的自己 课堂的例子很好, 但过于简单, 写得也很粗粘, 笔者 让他再次分析对应绘本中主人公的四个心路历程: 掩 饰、躲避、徘徊、请求。把这样的“武功招数”运用到 作文过程中，对照绘本，体会对应的心理变化。张同 学通过修改的作文片段:

开学写字课上, 老师让大家拿出习字册, 继续写 后面的内容, 她检查我在家前面的书写情况。我疫情 期间在家没有认真写, 趁妈妈不注意, 假装看网课, 其实在看游戏, 所以有部分习字册没有写完, 心里直 打鼓。看着本子上一片空白, 太惨不忍睹”了。完了, 我不知所措, 怎么办? 同学们都在继续认真写, 眼看 老师快检查到我们这组了, 我立刻用手捂住习字册空 白处，不让老师发现。

老师走到我跟前, 亲切地说: “你怎么不写了? ” 我的心提到了嗓子眼, 怦怦直跳: “.......我......我...... 马上换支笔写......”一边说着, 一边拿一本《语文补 充习题》, 悄悄遮挡在习字册上, 老师没说什么, 轻 轻地走了过去。

我想: 要不要告诉老师呢? 如果告诉被批评怎么 办? 如果不告诉, 这不是撒谎吗? 我怎么能做一个撒 谎的学生呢? 怎么办? 我眼睛盯着习字册, 半天没有 动笔。

这时, 同桌小敏发现了我像热锅上的蚂蚁, 轻声 问: “你怎么啦? ”我从习字册上拿开《补充习题》: “你看”, 小敏差点喊起来: “哦......”嘘——”我环视 四周, 用手指放在嘴角, 做了一个拉链的动作, “别 告诉老师......”。

本片段运用细淢的写作手法, 写出小作者内心的 紧张、纠结和矛盾, 很有画面感, 很打动人。

\subsection{2, 与家长的交流。}

王同学写了家长不能来参加家长会的事例, 家长 会开始前, 担心得“心怦怦直跳”。和家长进行了电话
沟通, 了解到该生家长确实工作繁忙, 家长向老师表 示了歉意。在充分理解和尊重家长的前提下, 请家长 和孩子一起读一读绘本故事, 体会孩子的内心烦恼, 请求家长协助完成习作修改。后来王同学在写出自己 心情的同时, 还写了自己和父母沟通成功后, “树叶 打着旋飘落在地上, 微风拂过绿色的草坪, 我的心又 怦怦跳了, 这一次, 我像快乐的小鸟, 赶快要跑步告 诉老师......”这一段写得形象生动, 受到大家的好评。

本次习作教学之后, 笔者深深感受到, 学生有一 些常见的心理障碍, 也有一些平时教师看不见而忽略 的心中烦恼, 教师要做孩子的知心朋友, 在生活中积 极引导孩子, 成为他们习作成长路上引导者, 带给他 们力量和希望, 这是每个教育工作者的追求。

\section{4. 案例结论}

习作教学结合心理教育, 围绕教育主题, 创设特 定情境, 让学生身临其境、亲身感受, 获得心理体验 [5], 让学生在课堂生活体验中学会表达, 学会写作。 写出来了, 也能减轻烦恼, 获得快乐。既培养良好的 心理品质, 又提高写作能力, 一举两得。

儿童的心理, 就像透明的水晶, 只要教师用心呵 护, 用智慧浇灌, 一定能开出美丽的花朵。

\section{REFERENCES}

[1] Ran, MJ. (2020) Attach importance to the cultivation of students' observation ability-return the teaching of assignments to the original point. Curriculum Teaching Research [J], 8: 37-40.

[2] Lin, BJ. (2014) How to optimize the mental structure in Chinese teaching and promote the development of students' mental health. Middle school Chinese [J], 27: 125-126.

[3] Wang, WJ. (2019) Tao Xingzhi's Educational Theory and Its Enlightenment on Composition Teaching in Primary Schools. Teaching Management and Educational Research [J], 21:24-26.

[4] Tang, YX. (2015) The effective application of psychological counseling technology in the conversation between the head teacher and the students. Middle school curriculum guidance (teaching research) [J], 13:98-98,104.

[5] Shen, SH. Li, JJ. (2012) Mental health education in primary and secondary schools[M]. Nanjing. Jiangsu Phoenix Science and Technology Press, Nanjing. 